\title{
Purification Testing for HEU Blend Program
}

by

M. C. Thompson

Westinghouse Savannah River Company

Savannah River Site

Aiken, South Carolina 29808

R. A. Pierce

This paper was prepared in connection with work done under the above contract number with the U.S. Department of Energy. By acceptance of this paper, the publisher and/or recipient acknowledges the U.S. Government's right to retain a nonexclusive, royalty-free license in and to any copyright covering this paper, along with the right to reproduce and to authorize others to reproduce all or part of the copyrighted paper.

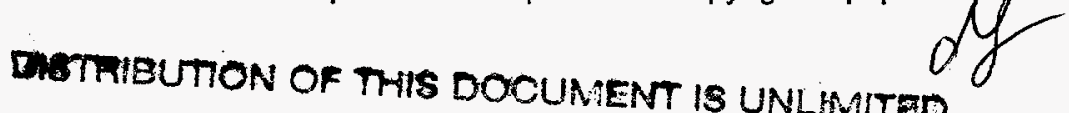




\section{DISCLAIMER}

This report was prepared as an account of work sponsored by an agency of the United States Government. Neither the United States Government nor any agency thereof, nor any of their employees, makes any warranty, express or implied, or assumes any legal liability or responsibility for the accuracy, completeness, or usefulness of any information, apparatus, product, or process disclosed, or represents that its use would not infringe privately owned rights. Reference herein to any specific commercial product, process, or service by trade name, trademark, manufacturer, or otherwise does not necessarily constitute or imply its endorsement, recommendation, or favoring by the United States Government or any agency thereof. The views and opinions of authors expressed herein do not necessarily state or reflect those of the United States Government or any agency thereof.

This report has been reproduced directly from the best available copy.

Available to DOE and DOE contractors from the Office of Scientific and Technical Information, P. O. Box 62, Oak Ridge, TN 37831; prices available from (423) 576-8401.

Available to the public from the National Technical Information Service, U. S. Department of Commerce, 5285 Port Royal Road, Springfield, VA 22161. 


\section{DISCLAIMER}

Portions of this document may be illegible in electronic image products. Images are produced from the best available original document. 
WSRC-TR-98-00233

Publication Date: June 1998

\title{
Purification Testing for HEU Blend Program (U)
}

\author{
R. A. Pierce and M. C. Thompson
}

Westinghouse Savannah River Company

Savannah River Site

Aiken, South Carolina 29808 
WSRC-TR-98-00233

Publication Date: June 1998

Purification Testing for HEU Blend Program (U)

R. A. Pierce and M. C. Thompson

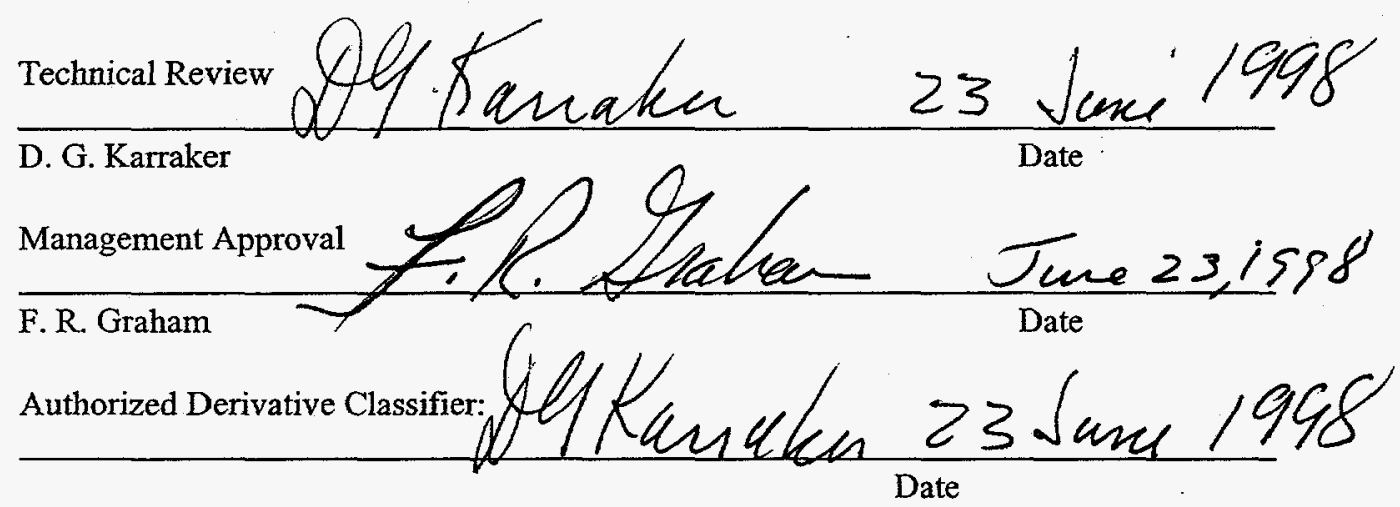

ii 


\section{Abstract}

The Savannah River Site (SRS) is working to dispose of the inventory of enriched uranium (EU) formerly used to make fuel for production reactors. The Tennessee Valley Authority (TVA) has agreed to take the material after blending the EU with either natural or depleted uranium to give a ${ }^{235} \mathrm{U}$ concentration of $4.8 \%$. The lowenriched uranium will be fabricated by a vendor into reactor fuel for use in TVA reactors. SRS prefers to blend the EU with existing depleted uranium (DU) solutions, however, the impurity concentrations in the DU and EU are so high that the blended material may not meet specifications agreed to with TVA. The principal nonradioactive impurities of concern are carbon, iron, phosphorus and sulfur. Neptunium and plutonium contamination levels are about 40 times greater than the desired specification.

Tests of solvent extraction and fuel preparation with solutions of SRS uranium demonstrate that the $\mathrm{UO}_{2}$ prepared from these solutions will meet specifications for $\mathrm{Fe}, \mathrm{P}$ and $\mathrm{S}$, but may not meet the specifications for carbon. The reasons for carbon remaining in the oxide at such high levels is not fully understood, but may be overcome either by treatment of the solutions with activated carbon or heating the $\mathrm{UO}_{3}$ in air for a longer time during the calcination step of fuel preparation.

Calculations of the expected removal of $\mathrm{Np}$ and $\mathrm{Pu}$ from the solutions show that the specification cannot be met with a single cycle of solvent extraction. The only way to ensure meeting the specification is dilution with natural $\mathrm{U}$ which contains no $\mathrm{Np}$ or $\mathrm{Pu}$. Estimations of the decontamination from fission products and daughter products in the decay chains for the $U$ isotopes show that the specification of $110 \mathrm{MEV} \mathrm{Bq} / \mathrm{g} U$ can be met as long as the activities of the daughters of U-235 and U-238 are excluded from the specification. 
WSRC-TR-98-00233

Publication Date: June 1998

\section{Contents}

Introduction 1

Discussion $\quad 1$

Tests for Non-Radioactive Contaminants $\quad 1$

$\mathrm{Np}$ and $\mathrm{Pu}$ Contamination 4

Gamma Contamination $\quad 5$

Conclusions $\quad 7$

References $\quad 7$

\section{List of Tables}

Table 1. Solution Composition for First Tests

Table 2. Results of Decontamination in Fuel Fabrication

Table 3. Results from Solvent Extraction Test

Table 4. Neptunium and Plutonium Contamination of Uranium Solutions

Table 5. Gamma Emitting Isotopes in Enriched Uranium Solutions

Table 6. Gamma Emitting Isotopes in Depleted Uranium Solutions 


\section{Introduction}

The Savannah River Site (SRS) is working to dispose of the inventory of enriched uranium (EU) formerly used to make fuel for production reactors. The Tennessee Valley Authority (TVA) has agreed to take the material after blending the EU with either natural or depleted uranium to give a ${ }^{235} \mathrm{U}$ concentration of $4.8 \%$. The lowenriched uranium will be fabricated by a vendor into reactor fuel for use in TVA reactors. SRS prefers to blend the EU with existing depleted uranium (DU) solutions, however, the impurity concentrations in the DU and EU are so high that the blended material may not meet specifications agreed to with TVA. The principal nonradioactive impurities of concern are carbon, iron, phosphorus and sulfur. Carbon and phosphorus are from residual tributyl phosphate (TBP) and dibutyl phosphate (DBP) remaining after reprocessing by solvent extraction with TBP based processes. Iron and sulfur are from ferrous sulfamate.(FS) used as a reductant for plutonium during reprocessing. The tests reported here were performed to determine the decontamination obtainable from the non-radioactive components during fuel fabrication processing. Testing of the effect of solvent extraction is also included to determine the overall effect of additional processing and the fuel fabrication process. Tests of removal of the radioactive impurities $\mathrm{Np}$ and $\mathrm{Pu}$ were estimated from past operations.

\section{Discussion}

The flow sheet favored by several fuel fabricators in the United States involves precipitation of $U$ by ammonium hydroxide to form ammonium diuranate. The ammonium diuranate is calcined to produce $\mathrm{UO}_{3}$ and then reduced to $\mathrm{UO}_{2}$ with hydrogen. The $\mathrm{UO}_{2}$ produced must meet the TVA specifications for use in their reactors. Tests were done spiking in only those impurities which have been shown to be high in the uranium solutions. Tests were done at the uranium concentration of the blended solution rather than the separate streams, however, the results are expected to be applicable to either stream if purified separately.

\section{Tests for Non-Radioactive Contaminants}

Tests of fuel fabrication were made with solutions containing U with DBP and TBP added to give carbon and phosphorus along with ferric nitrate and sulfuric acid to give iron and sulfur. The impurity concentrations were determined based on their concentrations in existing solutions being mixed to produce a final ${ }^{235} \mathrm{U}$ concentration of $4.8 \%$. The composition of the solution is shown in Table 1 . The value for $\mathrm{P}$ is shown as a less than number due to $U$ interference in the analytical method.

\section{Table 1. Solution Composition for First Tests}

$\begin{array}{lc}\text { Component } & \text { Concentration } \\ \text { Uranium } & 57 \mathrm{~g} / \mathrm{L} \\ \mathrm{HNO}_{3} & 0.1 \mathrm{M} \\ \text { Carbon } & 2790 \mu \mathrm{g} / \mathrm{g} \mathrm{U}^{*} \\ \text { Iron } & 1070 \mu \mathrm{g} / \mathrm{g} \mathrm{U}^{*} \\ \text { Phosphorus } & <400 \mu \mathrm{g} / \mathrm{g} \mathrm{U}^{*} \\ \text { Sulfur as sulfate } & 15663 \mu \mathrm{g} / \mathrm{g} \mathrm{U}^{*} \\ { }^{*} \text { Micrograms per } \mathrm{g} \mathrm{U} & \end{array}$


In the first tests, the prepared solution was divided into two equal parts with one portion being washed with nparaffin and one being untreated. Each portion was then treated to precipitate uranium by adding a $50 \%$ stoichiometric excess of concentrated $\mathrm{NH}_{4} \mathrm{OH}$, then filtered, washed with three portions of $0.5 \mathrm{M} \mathrm{NH}_{4} \mathrm{OH}$, air dried, and calcined at $450^{\circ} \mathrm{C}$ for one hour. The solids were sampled for analysis after cooling to ambient temperature. All solutions were sampled and submitted for analysis. Problems were encountered with obtaining complete dissolution of DBP and TBP in the solutions and with the measurement of $\mathrm{P}$ by emission spectroscopy. The latter problem was a result of $U$ spectral interference resulting in a high detectability limit for $P$. Table 2 shows the concentrations of the impurities in the oxide and the decontamination factors (DF).

Table 2. Results of Decontamination in Fuel Fabrication

$\begin{array}{lcccc}\text { Impurity } & \begin{array}{c}\text { No Diluent Wash } \\ \text { Conc'n, } \mu \mathrm{g} / \mathbf{g} \mathbf{~ U}\end{array} & \begin{array}{c}\text { Diluent Wash } \\ \text { Conc'n, } \mu \mathbf{g} / \mathbf{g} \mathbf{U}\end{array} & \begin{array}{c}\text { No Diluent Wash } \\ \text { DF }\end{array} & \begin{array}{c}\text { Diluent Wash } \\ \text { DF }\end{array} \\ \text { Carbon } & 597 & 1058 & 4.7 & 2.6 \\ \text { Phosphorus } & <400 & <400 & \text { NC } & \text { NC } \\ \text { Iron } & 775 & 664 & 1.4 & 2.8 \\ \text { Sulfur } & 1625 & 221 & 9.6 & 70.7 \\ \text { NC = Not Calculated } & & & & \end{array}$

The carbon content of the washed material was higher than for the unwashed material. The n-paraffin wash should not increase the carbon. Since n-paraffin does not remove DBP from aqueous solutions, the difference is either due to a non-homogeneous sample or problems in sample analysis. Dibutyl phosphoric acid tends to adhere to plastic surfaces so it is possible that the difference was a result of contacting plastic surfaces during solution handling. Overall the DF is expected to be low because addition of base results in precipitation of uranyl dibutyl phosphate complexes carrying the carbon and phosphorus into the oxide product. Little decontamination from iron was expected because ferric hydroxide is highly insoluble in base. The decontamination from sulfate is in the expected range. Additional decontamination could be obtained by washing more. However, a DF of 70 is adequate to meet the specification of $<15 \mu \mathrm{g} / \mathrm{g} \mathrm{U}$, if the initial sulfur concentration is $<1000 \mu \mathrm{g} / \mathrm{g} \mathrm{U}$.

All solutions will be processed through solvent extraction to remove impurities especially the $\mathrm{Pu}, \mathrm{Np}$, and $\mathrm{Fe}$ which precipitate along with $U$ in ammonium hydroxide solution. Thus, a second set of tests included batch solvent extraction to determine the overall purification obtained with processing existing solutions through a cycle of solvent extraction prior to fuel fabrication. Solution was prepared by dissolving $45 \mathrm{~g}$ of uranyl nitrate hexahydrate in $100 \mathrm{~mL}$ of $0.1 \mathrm{M} \mathrm{HNO}_{3}$, adding $0.0271 \mathrm{~g}$ of $96 \mathrm{wt} \% \mathrm{H}_{2} \mathrm{SO}_{4}$, and $0.181 \mathrm{~g}$ of Fe$\left(\mathrm{NO}_{3}\right)_{3} 9 \mathrm{H}_{2} \mathrm{O}$. Solution analyses showed $190 \mathrm{~g} / \mathrm{L} \mathrm{U}$ with $1179 \mu \mathrm{g} \mathrm{SO}{ }_{4}^{2-} / \mathrm{g} \mathrm{U}$ and $1170 \mu \mathrm{g} \mathrm{Fe} / \mathrm{g} \mathrm{U}$. The solution was made $0.012 \mathrm{M}$ ferrous sulfamate (FS) by adding 1.8 M FS solution (FS is the reductant used to reduce $\mathrm{Pu}$ and improve decontamination). Then $59 \mathrm{~mL}$ of $1.5 \mathrm{M} \mathrm{HNO}_{3}$ was added to increase acidity and aid extraction. After mixing the aqueous solutions in a separatory funnel, $450 \mathrm{~mL}$ of 30 vol.\% TBP n-paraffin was added and the solutions were mixed in the separatory funnel. The aqueous was drained out for disposal. Twenty-nine $\mathrm{mL}$ of $1.5 \mathrm{M} \mathrm{HNO}_{3}$ was added and the organic and aqueous shaken together to scrub the solution. The aqueous was drained and $30 \mathrm{~mL}$ of water was added to reduce the acid concentration prior to stripping the $U$ into two 225 $\mathrm{mL}$ portions of $0.08 \mathrm{M} \mathrm{HNO}_{3}$. The strip solutions were combined, sampled, and divided into two equal portions. One portion was washed with a small portion of fresh plant diluent ( $n$-paraffin) prior to further processing. Samples were taken from both the washed and unwashed aqueous solutions for $U$ and impurity analyses. Both solutions were then treated by the following steps representative of preparation of $\mathrm{UO}_{2}$ powder for fuel fabrication. 
Uranium was precipitated as ammonium diuranate by addition of a $50 \%$ stoichiometric excess of concentrated $\mathrm{NH}_{4} \mathrm{OH}$, filtered through a stainless steel filter frit, and washed 3 times with $0.5 \mathrm{M} \mathrm{NH}_{4} \mathrm{OH}$. After air drying with vacuum, the solids were transferred to a quartz crucible and heated at $450 \mathrm{C}$ in an air atmosphere for $1 \mathrm{hr}$ to convert to $\mathrm{UO}_{3}$. After cooling the $\mathrm{UO}_{3}$ solids were stirred and sampled for analyses. The remaining $\mathrm{UO}_{3}$ was placed in a quartz boat in a tube furnace and heated for 3-4 hours in a stream of 4 vol\% hydrogen in argon at $700^{\circ} \mathrm{C}$ for conversion to $\mathrm{UO}_{2}$. The $\mathrm{UO}_{2}$ was cooled, stirred, and sampled for analyses. Table 3 summarizes the impurity concentrations obtained in the test.

The carbon concentration in the initial solution was not measured because the TBP solvent would add far more carbon than was present initially. The very high $\mathrm{C}$ concentration in the unwashed solution after solvent extraction is due to dissolved TBP as shown by the high removal during washing with n-paraffin. The subsequent increase after precipitation and calcination is unknown. However, the differences could be due to the first two analyses being made on solutions while the latter four analyses were made directly on the solid oxides. There are other questions about the $\mathrm{C}$ data in that the $\mathrm{UO}_{2}$ from n-paraffin washed solution had higher $\mathrm{C}$ than $\mathrm{UO}_{2}$ from unwashed solution. This may indicate contamination during handling of the samples rather than actual removal efficiencies. The earlier test shown in Table 2 indicate a DF of 2.6-4.6 should be obtained during the fuel manufacturing steps. Assuming that to be the case, the $\mathrm{C}$ content of material after solvent washing to remove TBP would be less than the specification of $200 \mu \mathrm{g} / \mathrm{g} \mathrm{U}$. Alternatively, diluting with natural $\mathrm{U}$ instead of the DU would bring the $\mathrm{C}$ within the desired specification.

Table 3. Results from Solvent Extraction Test

Test Step
Initial Solution
Solvent Extraction Product - Unwashed
Solvent Extraction Product - n-paraffin Washed
$\mathrm{UO}_{3}$ from Unwashed Solution
$\mathrm{UO}_{3}$ from n-paraffin Washed Solution
$\mathrm{UO}_{2}$ from Unwashed Solution
$\mathrm{UO}_{2}$ from n-paraffin Washed Solution
Proposed TVA Specification
NA = Not Analyzed

\section{Test Step}

Solvent Extraction Product - Unwashed

$\mathrm{UO}_{3}$ from Unwashed Solution

$\mathrm{UO}_{2}$ from Unwashed Solution

$\mathrm{UO}_{2}$ from n-paraffin Washed
Proposed TVA Specification

$\mathrm{NA}=$ Not Analyzed

$\begin{array}{rr}\mathrm{C}, \mu \mathrm{g} / \mathrm{gU} & \mathrm{Fe}, \mu \mathrm{g} / \mathrm{gU} \\ \mathrm{NA} & 19300 \\ 48200 & <160 \\ 420 & <160 \\ 2300 & \mathrm{NA} \\ 1800 & \mathrm{NA} \\ 1020, & \mathrm{NA} \\ 1400 & \mathrm{NA} \\ 200 & 250\end{array}$

$\mathbf{P}, \mu \mathrm{g} / \mathbf{g ~ U}$
NA
NA
NA
$<510$
160
140
250
250
$\underline{\mathbf{S}}, \boldsymbol{\mu g} / \mathbf{g} \mathbf{U}$
4400
88
70
210
170
140
120
100

The concentrations of $\mathrm{Fe}$ and $\mathrm{S}$ in the initial solution are the total of that added initially plus that present from the FS. Iron concentrations in the solvent extraction product solutions were below the detectability limits for the analytical method. Unless $\mathrm{Fe}$ contamination from corrosion or added chemicals increased the $\mathrm{Fe}$ concentration, the value obtained would be within the proposed specifications for acceptance by TVA (250 $\mu \mathrm{g} / \mathrm{g} \mathrm{U}$ ). Consequently Fe was not analyzed in the solid products.

Phosphorus was not analyzed in the initial solutions because the interference from $U$ would make the results meaningless. Phosphate ion was analyzed by ion chromatography in the $\mathrm{UO}_{3}$ and $\mathrm{UO}_{2}$ products after dissolution in $\mathrm{HNO}_{3}$. Ion chromatography has a detection limit for $\mathrm{PO}_{4}{ }^{3-}$ which is very close to the values obtained for these solutions. In fact, the $\mathrm{UO}_{3}$ made from unwashed solution was given as a less than value because the value was below the detection limit. The phosphorus concentration was calculated from the measured $\mathrm{U}$ and $\mathrm{PO}_{4}{ }^{3-}$ concentrations. The data show that the $\mathrm{UO}_{2}$ product will be at or within the proposed specification of $250 \mu \mathrm{g} / \mathrm{g} \mathrm{U}$. It is interesting to note that the $\mathrm{C}$ and $\mathrm{P}$ analyses for the washed and unwashed $\mathrm{UO}_{2}$ products correspond in that both analyses are higher for the washed sample than for the unwashed sample. 
The analyses are the opposite of what is expected from the chemistry, the solution analyses, and the analyses of the $\mathrm{UO}_{3}$.

The data indicates that the specification for sulfur was not met in this test. However, this test used only one stage of scrubbing to remove impurities. At least 3 scrub stages will be present between the addition of FS and exit from the mixer settler during plant operations. The decontamination factor shown here for one stage of scrubbing is about $35(4400 / 126)$. Each scrub stage can be expected to give a decontamination factor of at least 5-10. Thus, the minimum decontamination factor for 3 scrub stages would be $5 \times 5 \times 5$, which is 125 . Decontamination by a factor of 125 should give a product with $35 \mu \mathrm{g} / \mathrm{g} \mathrm{U}$, which is well within the specification of $100 \mu \mathrm{g} / \mathrm{g} \mathrm{U}$. An overall decontamination factor of only 50 would bring the $S$ concentration below $100 \mu \mathrm{g} / \mathrm{g} U$. Thus, solvent extraction can be expected to result in a product that meets the specifications for $\mathrm{S}$.

All analyses were performed by the Analytical Development Section of the Savannah River Technology Center using standard analytical methods with NIST traceable standards. Uranium was analyzed by a Chem Check ${ }^{\mathrm{TM}}$ instrument using $U$ phosphorescence. Acid was determined by titration with $\mathrm{NaOH}$ after complexation of metal ions. Carbon was determined using a $\mathrm{LECO}^{\mathrm{TM}}$ instrument in which the sample is oxidized in a stream of oxygen with $\mathrm{CO}_{2}$ being measured by infrared spectroscopy. Iron and phosphorus were determined by ioncoupled plasma emission spectroscopy (ICP-ES). Sulfate was determined by ion chromatography and sulfur was calculated from sulfate. High concentrations of nitrate as were present in these solutions reduces the detection limit for sulfate ion. Ion chromatography cannot be used to analyze for concentrations lower than about $75 \mu \mathrm{g} / \mathrm{g} \mathrm{U}$ unless the nitrate ion is removed by a pretreatment step. Such a pretreatment step is not presently used in our analytical laboratories. Analyses for phosphate and sulfate ions in uranium oxide solids was done by first dissolving the solids in dilute $\mathrm{HNO}_{3}$ solution, evaporating to dryness at ambient temperature with an air flow across the top of the beaker and then re-dissolving in deionized water. This procedure was followed to minimize interference from nitrate ion during analyses.

\section{Np and Pu Contamination}

These tests did not include $\mathrm{Np}$ or $\mathrm{Pu}$ which are above the desired specifications. The activities of $\mathrm{Np}$ and $\mathrm{Pu}$ in the EU and DU solutions are shown in Table 4 along with the expected decontamination factors based on past performance of second $\mathrm{U}$ cycle in $\mathrm{F}$ and $\mathrm{H}$ canyons. The decontamination from $\mathrm{Pu}$ is better than for $\mathrm{Np}$ at

Table 4. Neptunium and Plutonium Contamination of Uranium Solutions

\begin{tabular}{lccccc} 
& \multicolumn{2}{c}{ Existing Solutions } & \multicolumn{2}{c}{$\mathbf{2}^{\text {nd }}$ Cycle } & \multicolumn{2}{c}{ Purified Solutions } \\
Radionuclide & $\underline{\mathbf{E U}}$ & $\underline{\mathbf{D U}}$ & $\underline{\mathrm{DF}}$ & $\underline{\mathbf{E U}}$ & $\underline{\mathbf{D U}}$ \\
$\mathrm{Np}$ & $665 \underline{\mathrm{Bq} / \mathrm{g} \mathrm{U}}$ & $217 \mathrm{~Bq} / \mathrm{g} \mathrm{U}$ & $\mathrm{EU}=9, \mathrm{DU}=3$ & $74 \mathrm{~Bq} / \mathrm{g} \mathrm{U}$ & $72 \mathrm{~Bq} / \mathrm{g} \mathrm{U}$ \\
$\mathrm{Pu}$ & $231 \mathrm{~Bq} / \mathrm{g} \mathrm{U}$ & $461 \mathrm{~Bq} / \mathrm{g} \mathrm{U}$ & $\mathrm{EU}=10, \mathrm{DU}=20$ & $23 \mathrm{~Bq} / \mathrm{g} \mathrm{U}$ & $23 \mathrm{~Bq} / \mathrm{g} \mathrm{U}$
\end{tabular}

comparable concentrations in the feed stream because FS is added to reduce $\mathrm{Pu}$ from the extractable $\mathrm{Pu}(\mathrm{IV})$ to inextractable $\mathrm{Pu}(\mathrm{III})$ (see Equation 1 below). The addition of reductant, however, increases $\mathrm{Np}$ extractability by reducing inextractable $\mathrm{Np}(\mathrm{V})$ to extractable $\mathrm{Np}(\mathrm{IV})$ (see Equation 2 below).

$$
\begin{aligned}
& \mathrm{Pu}^{4+}+\mathrm{Fe}^{2+} \rightarrow \mathrm{Pu}^{3+}+\mathrm{Fe}^{3+} \\
& \mathrm{NpO}_{2}{ }^{1+}+\mathrm{Fe}^{2+}+4 \mathrm{H}^{+} \rightarrow \mathrm{Np}^{4+}+\mathrm{Fe}^{3+}+2 \mathrm{H}_{2} \mathrm{O}
\end{aligned}
$$


A part of the problem is probably associated with cross contamination from previous solutions. Extensive flushing might increase the DFs slightly; however, the entrainment of aqueous in the organic phase in the mixer settlers also contributes to the low DF and is not readily overcome without extensive equipment changes. The data shows that reduction of both $\mathrm{Np}$ and $\mathrm{Pu}$ in a single pass through the second uranium cycle is difficult to achieve. The contamination levels which can be achieved by a single cycle of solvent extraction will not produce solution within the desired TVA specification of $25 \mathrm{~Bq} / \mathrm{g} \mathrm{U}$. It is possible with two cycles of solvent extraction where no reductant is added in one of the cycles could decrease the Np contamination closer to that for $\mathrm{Pu}$, but the total would still be about two times higher than the desired specification of $25 \mathrm{~Bq} / \mathrm{g} \mathrm{U}$. Dilution with natural $\mathrm{U}$, which contains no $\mathrm{Np}$ or $\mathrm{Pu}$, would bring the total $\mathrm{Np}-\mathrm{Pu}$ within the specification without a second cycle of solvent extraction.

\section{Gamma Contamination}

The gamma activity of the solutions is higher than the specification of $110 \mathrm{MEV} \mathrm{Bq} / \mathrm{g} \mathrm{U}$. The gamma activity is from fission products and daughter products in the decay chains of the various $U$ isotopes. The largest contributor are from the U-236 decay chain which is shown in Figure $1 .^{1}$ The efficiency of the second U solvent extraction cycle removal of the gamma activity will vary depending on the element and concentration.

Figure 1. Decays Chains for the Principal Uranium Isotopes
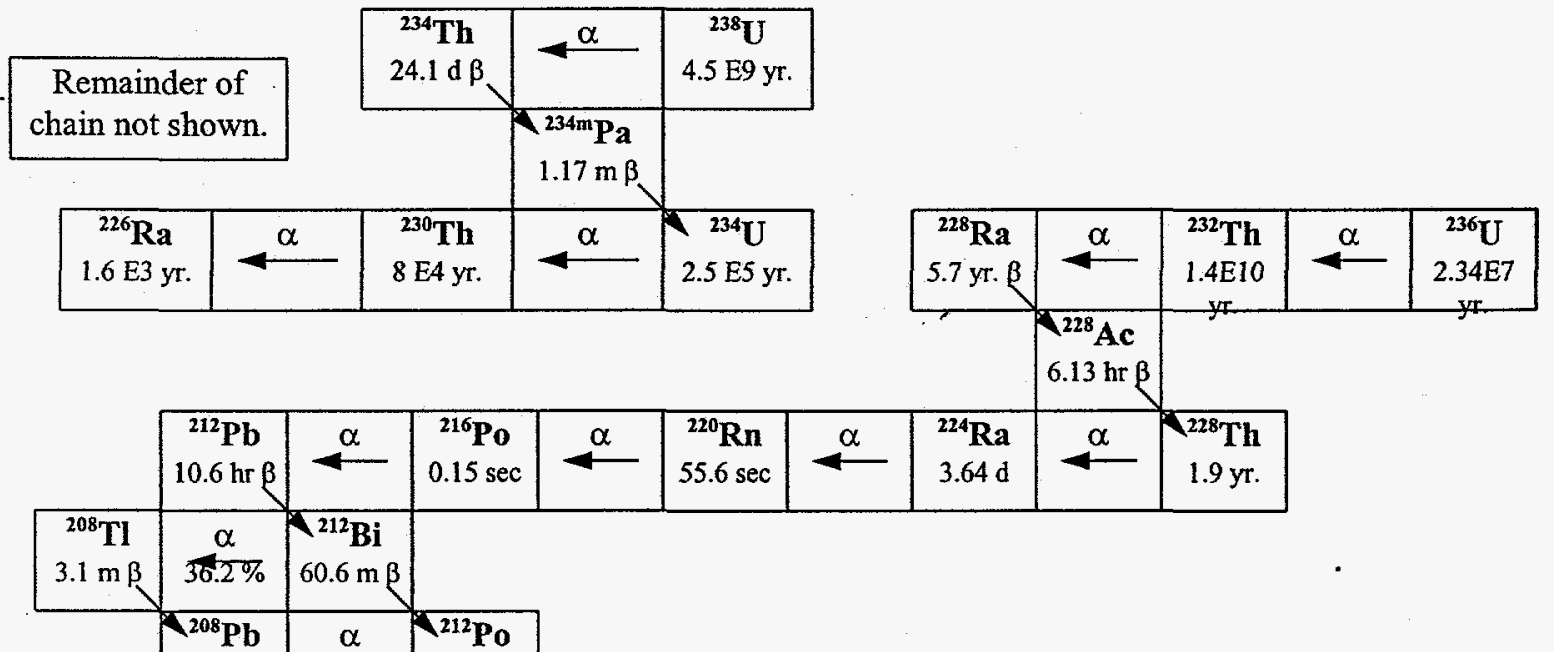

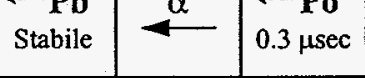

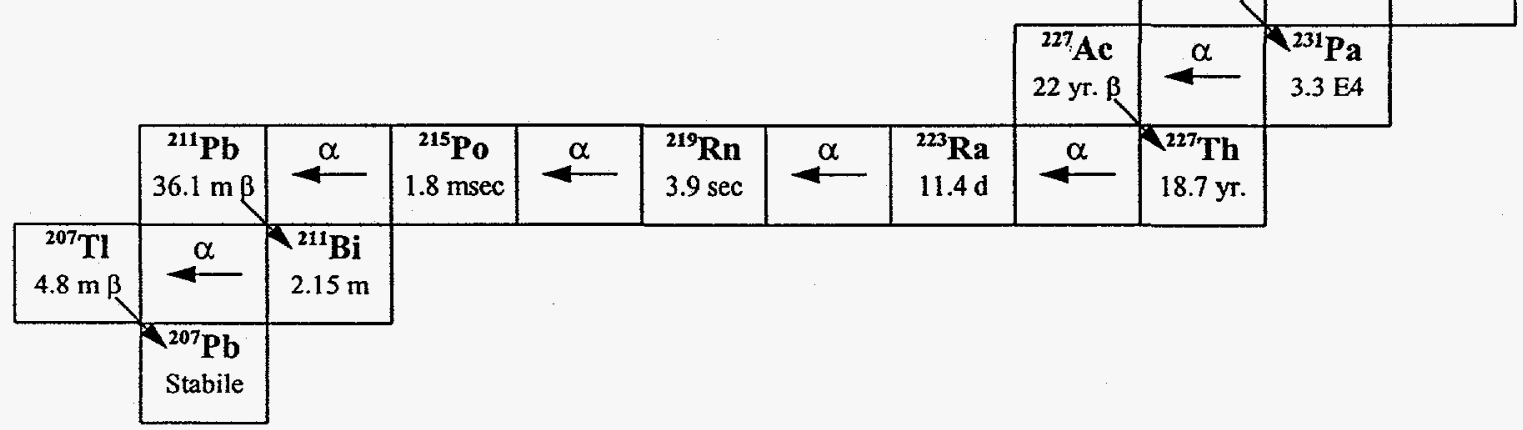


Table 5 shows the principal contributors to the gamma activity in the HEU solutions as reported in a recent analysis from the Y-12 laboratory at Oak Ridge.

Table 5. Gamma Emitting Isotopes in Enriched Uranium Solutions

\author{
Element and Isotope \\ I-132 - Fission Product \\ Ra-224 - U-236 Chain \\ Th-231 - U-235 Chain \\ Bi-212 - U-236 Chain \\ $\mathrm{Pb}-212$ - U-236 Chain \\ Tl-208 - U-236 Chain \\ Zr-95 - Fission Product \\ All others \\ Totals
}

\begin{tabular}{c} 
Gamma Activity, \\
MEV Bq/g U \\
\hline 230 \\
150 \\
1200 \\
770 \\
1900 \\
14,000 \\
150 \\
210 \\
18,610
\end{tabular}

Expected DF
$1.5-2$
$150-200$
$100-150$
$90-100$
$150-200$
$90-100$
$1-2$
$2-3$
$31-44$

\begin{tabular}{c}
$\begin{array}{c}\text { Final Activity, } \\
\text { MEV Bq/g U }\end{array}$ \\
\hline $115-150$ \\
1 \\
$8-12$ \\
$8-9$ \\
$10-13$ \\
$140-160$ \\
$75-150$ \\
$70-105$ \\
$427-600$
\end{tabular}

The expected DFs were estimated on the basis of performance for $\mathrm{Pu}$ as a function of activity in the feed $(\mathrm{d} / \mathrm{m} / \mathrm{mL})$ to the second $U$ cycle in $\mathrm{H}$ canyon except for Th which was based on $\mathrm{Np}$ performance as a function of activity. Thorium DF should be slightly higher than Np because the distribution coefficient of $\mathrm{Th}(\mathrm{IV})$ is lower than that of $\mathrm{Np}$ (IV). The Tl-208 has only a 3.1 minute half-life, so it will decay in less than 30 minutes to a level that is in equilibrium with its $\mathrm{Bi}-212$ precursor. Therefore, the DF for Tl-208 was based on the DF for $\mathrm{Bi}-212$. A range is given for the DF and the final activity because actual performance is variable. The HEU solution after solvent extraction will have much lower gamma activity, but will not be within the specification before dilution. It is surprising that fission products such as $\mathrm{Zr}-95$ and $\mathrm{I}-132$ are still present to significant activity because of their short half-lives, 65 day and 2.3 hour, respectively. This may be the level which is maintained in solution due to fissions occurring in solution.

All of the daughter gamma activities from U-235 and U-236 will grow back into the solution after separation as shown in Figure 1. Radioactivity from Th-231, the first daughter in the U-235 chain, grows back into equilibrium in $<30$ days because of the short half-life of Th- 231 ( 25.6 hours). All radioactivity from decay of U-235 should be excluded from the specification because it will always be in equilibrium corresponding to the U-235 concentration in solution. This means that there will be $95 \mathrm{MEV} \mathrm{Bq} / \mathrm{g} \mathrm{U}$ from Th-231 in any solution containing $4.8 \mathrm{wt} \% \mathrm{U}-235$ including virgin material from enrichment of natural $\mathrm{U}$. The daughter products from U-236 are higher than from virgin enriched $U$. The decay chain for U-236 in Figure 1 shows that the half-lives of Ra-224 and the remainder of the chain are a few days or less, which is the reason the gamma activities are high. The short half lives result in rapid decay to equilibrium with the precursor activity Th-228, which was not determined in recent analyses. However, the half-lives of U-235 and Pa-231 are long enough that it will take years to reach the same activity levels obtained here

The gamma activity in the DU solution is lower because the U-238 has a longer half-life and the decay chain has fewer high energy gamma emitting nuclides. Table 6 shows information similar to Table 5, but for the DU solution. The DFs for Th and Ru were estimated in the same manner as in the case of HEU above. The DF for $\mathrm{Pa}$ was made the same as for its precursor $\mathrm{Th}$. The $\mathrm{DF}$ for $\mathrm{Nb}-95$ was set to be that expected for $\mathrm{Zr}-95$ its precursor which is very low. As shown in the table, the DFs should be sufficient to bring the DU well within the specification. The reason for this is that high DFs are expected for the two highest activities. As noted above early purification of the solutions would allow the Th and Pa activities to grow back in since they result from decay of U-238. Figure 2 shows the growth of Th-234 into the solution from U-238 decay. 
Table 6. Gamma Emitting Isotopes in Depleted Uranium Solutions

Element and Isotope

Pa-234m - U-238 Chain

Th-234 - U-238 Chain

Nb-95 - Fission Product

Ru-106 - Fission Product

All others

Totals

\begin{tabular}{c} 
Gamma Activity, \\
MEV Bq/g U \\
\hline 220 \\
110 \\
40 \\
50 \\
50 \\
470
\end{tabular}

\begin{tabular}{c} 
Expected DF \\
\hline $100-150$ \\
$100-150$ \\
$1-2$ \\
$10-15$ \\
$2-3$ \\
$6-11$
\end{tabular}

\begin{tabular}{c} 
Final Activity, \\
MEV Bq/g U \\
\hline $1.4-2$ \\
$0.7-1$ \\
$20-40$ \\
$3-5$ \\
$17-25$ \\
$42-73$
\end{tabular}

The calculations were made using the following equation where $N_{1}$ is the atoms of U-238 in a gram of DU, $N_{2}$ is the atoms of Th-234, superscript 0 represents the atoms at time $=0$, and $\lambda_{1}$ and $\lambda_{2}$ are the respective decay constants. $^{2}$

$\mathrm{N}_{2}=\lambda_{1} / \lambda_{2}-\lambda_{1} * N_{1}{ }^{0} *\left(\exp \left(-\lambda_{1} \mathrm{t}\right)-\exp \left(-\lambda_{2} \mathrm{t}\right)\right)+\mathrm{N}_{2}{ }^{0} * \exp \left(-\lambda_{2} \mathrm{t}\right)$

The term $\mathrm{N}_{2}{ }^{0}$ was assumed to be zero for the graph, so the second term dropped out. Note that within about 150 days the $\mathrm{Th}-234$ has reached secular equilibrium. In addition, the $\mathrm{Pa}-234 \mathrm{~m}$ with a half life of only 1.17 minutes will also be at equilibrium.

Figure 2. Rate of Formation of Th-234 from One Gram of Depleted Uranium

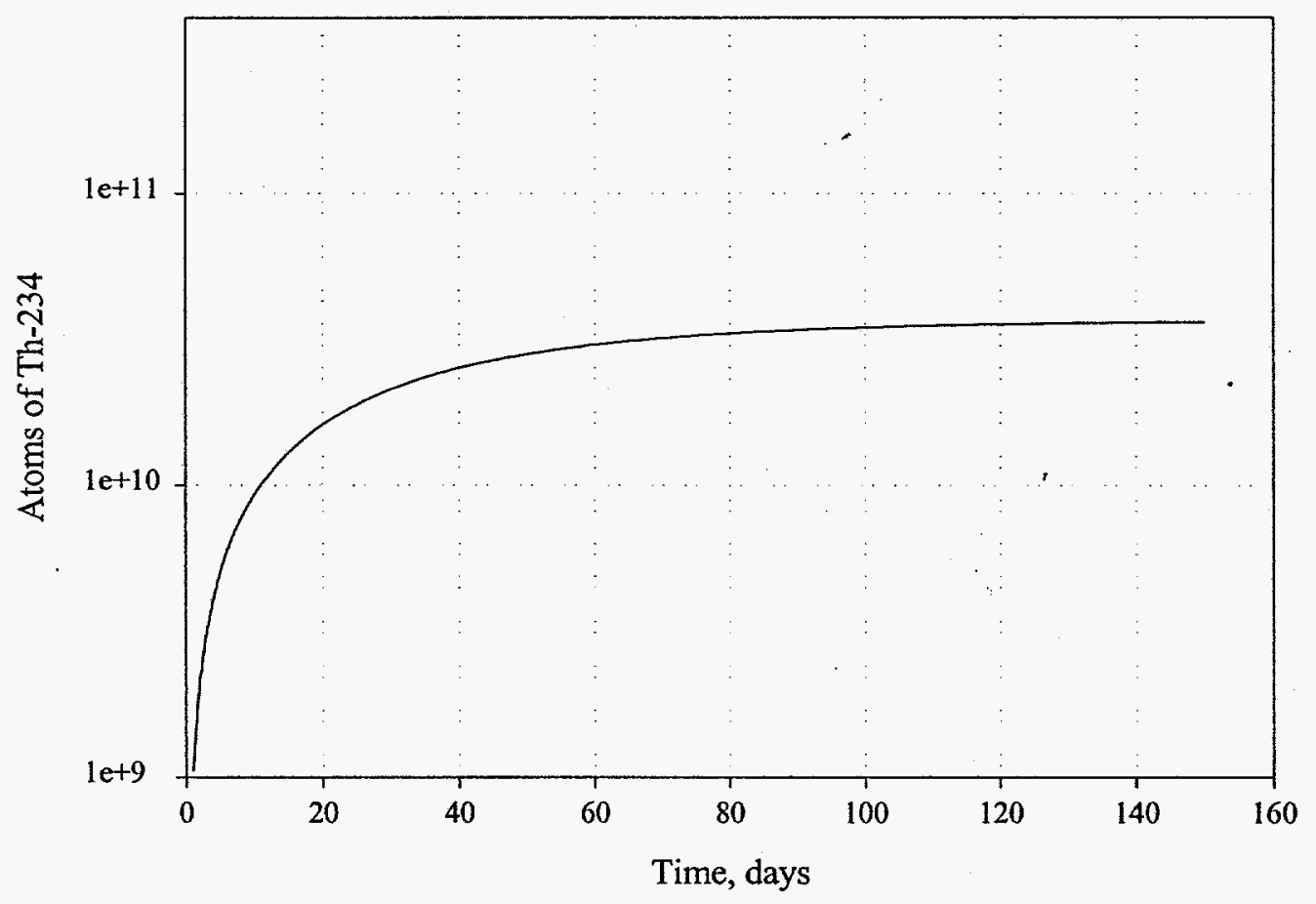


The activities of the daughters of U-238 should be excluded from the specification because they will be there at about the same level in natural $U$ and any enriched $U$. Mixing of the purified solutions to make $4.8 \mathrm{wt} \% \mathrm{U}-235$ would give solution with gamma activity between 61 and $97 \mathrm{MEV} \mathrm{Bq} / \mathrm{g} \mathrm{U}$ assuming the HEU is $60.5 \mathrm{wt} \% \mathrm{U}-$ 235 and the DU is $0.244 \mathrm{wt} \%$ U-235 and excluding U-235 and U-238 daughter gamma activities. Thus, it appears feasible that the specification of $110 \mathrm{MEV} \mathrm{Bq} / \mathrm{g} \mathrm{U}$ can be met by purification of both $\mathrm{U}$ solutions prior to mixing. However, purification of the HEU should be done shortly before mixing of the solutions to minimize effects of decay of $U$ isotopes increasing the gamma activity out of the desired range.

\section{Conclusions}

Tests of solvent extraction and fuel preparation with solutions of SRS uranium demonstrate that the $\mathrm{UO}_{2}$ prepared from these solutions will meet specifications for $\mathrm{Fe}, \mathrm{P}$ and $\mathrm{S}$, but may not meet the specifications for carbon. The reasons for carbon remaining in the oxide at such high levels is not fully understood, but may be overcome either by treatment of the solutions with activated carbon or heating the $\mathrm{UO}_{3}$ in air for a longer time during the calcination step of fuel preparation.

Estimations of the expected removal of $\mathrm{Np}$ and $\mathrm{Pu}$ from the solutions show that the specification cannot be met with a single cycle of solvent extraction. The only way to ensure meeting the specification is dilution with natural $\mathrm{U}$ which contains no $\mathrm{Np}$ or $\mathrm{Pu}$. Estimations of the decontamination from fission products and daughter products in the decay chains for the $U$ isotopes show that the specification of $110 \mathrm{MEV} \mathrm{Bq} / \mathrm{g} \mathrm{U}$ can be met as long as the activities of the daughters of U-235 and U-238 are excluded from the specification.

\section{References}

1. W. Seelmann-Eggebert, G. Pfennig, H. Munzel, and H. Klewe-Nebenius. Chart of the Nuclides, Druckhaus Haberbeck, Lippe, Ger. (1981)

2. G. Friedlander, J. W. Kennedy, E. S. Macias, and J. M. Miller. Nuclear and Radiochemistry, p. 191-199, John Wiley \& Sons, New York, NY (1981) 
Distribution List for WSRC-TR-98-00233

J. S. Evans, 703-F

Donald Johnson, 704-2H

Steven Yano, 704-2H

Richard Frushour, 704-2H

David Dolin, 704-2H

D. L.McWhorten, 704-F

Tom Campbell, 221-F

Fitz Trumble, 704-2H

Michael Lewcyzk, 221-14H

Charles Goergen, 221-H

Scott Federman, 221-H

Kenneth Fuller, 221-H

Gary Peterson, 703-F

J. R. Knight, 773-A

F. R. Graham, 773-A

E. A. Kyser, 773-A

R. A. Pierce, 773-A

M. C. Thompson, 773-A

D. G. Karraker, 773-A 